On $11^{\text {th }}$ March 2015, the gallant Tom Spooner and brave Simon King struck a course northwest on the Grand Union Canal, exploiting the terrain and the psycho-social boundaries imposed upon them by the city. They have left this message in the hope that others may come and join them in a great urban gathering at the Twyford aqueduct to celebrate their autonomy. - Message in a bottle

We met on a post-rush hour weekday morning on the concourse at Paddington Station. On your recommendation I had been reading up on Phil Smith's walking methodology, Mythogeography. Whilst we ate a hurried breakfast of pastries and coffee outside one of the food kiosks, we read aloud from Phil's published writings some of the highlights of his mytho approach to walking - much of it was reminiscent of Situationist psychogeography. The texts, we agreed, offered compelling, and at times ludic(rous) insights into walking, or drifting, in non-places, as a process of challenging the monuments of commercial tourism, and transforming overlooked areas of the public realm into sites of reverie and wonder. There are accounts in Smith of walkers operating under outlandish pseudonyms, such as "The Crab Man", and "Ninjalicious", defying and walking out on "The Spectacle", an unashamed nod to Guy Debord's 1967 text. However, we agreed it would be foolhardy to blindly follow this dogma, which also stipulates in The Handbook of Drifting: "20/ Displace your erotic feelings for each other to the landscape."

Under dull skies and suitably swaddled against an occasionally chilly breeze we set out from Paddington Station in a fairly uneventful start to our walk and where soon the soulless edifices and walkways of the Paddington Basin beyond the Westway begin to be replaced by the more salubrious environs (pristinely detached houses and lush greenery) of Maida Vale and Little Venice which nestle around an opening on to the Grand Union Canal. 


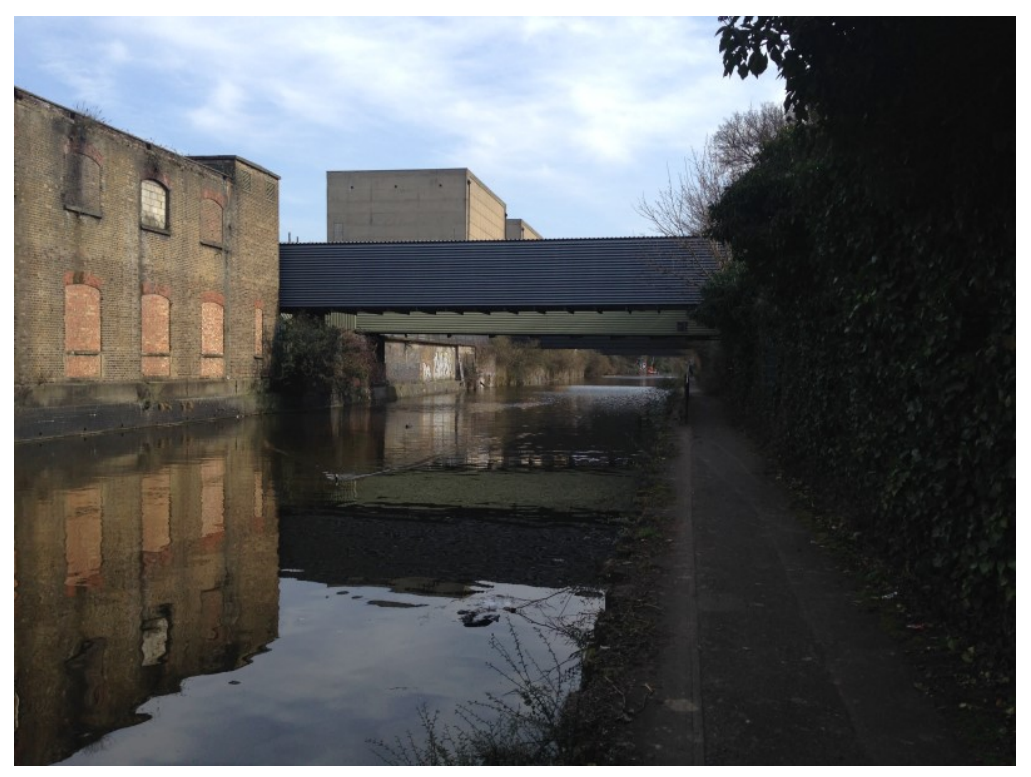

I had already decided that we would walk part of the Paddington branch of the canal because much of it as far as I was aware still resisted gentrification and was occupied predominantly by rundown and unremarkable industrial estates. This I had hoped would open up more opportunity for the sense of play and spontaneity, so fetishized in Smith's writing, and indeed, by the Situationists in their hunt for sites of psychogeographical curiosity. Having read Smith, I anticipated the dialectic that might unfold or suggest itself, where the critical would come to merge with the absurd in a new urban awareness.

I had encountered sections of the canal a few years earlier as an impoverished undergraduate based in the Harrow area, commuting to and from the city by bicycle. There was something I had experienced there in its desolate hinterland which drew me back. It was something ineffable, an aesthetic appeal maybe, embedded beneath my consciousness. I might describe my actions now as a neo-romantic ruin lust, a yearning for that clearing in the woods, where the emotionally dulling technological canopy of the city dissipates in a fleeting, and almost revelatory, moment. I wanted to resummon those spirits, internal or external, that I had felt previously but only in passing, and in isolation.

\section{The walk}

Following the canal, we head northwest, away from the idyllic sights of Little Venice. Curious cardboard markers, freshly taped to trees and lampposts along the way, provide some amusement. We speculate whether we are following someone's directions to an illegal squat party, or retracing part of a 
charity fun run, or whether they simply have something to do with directing the steady flow of barges on the canal beside us.

The boats seem to cruise along at their own pace, as autonomous entities, quite removed from the regulated, sanity-grating, stop-start, traffic systems we are so unnaturally acclimatized to in the city. It's quite soothing, hypnotic almost.

We re-join the Westway briefly and trek past barren stretches and graffiticovered pillars, rubble, and broken glass, beneath it. Its weather-battered supports, and exposed underside, reverberate with community unrest. Nearby, a considerable walk from anywhere, someone has dumped a pile of old furniture. An England flag tied to a makeshift mast has been dashed, along with this fly-tipper's dreams we presume, into the abandoned heap. A notice is attached, helpfully encouraging passers-by to take whatever they want.

A graffiti culture has evidently been growing for some years all along the canal side. Some of the harder to reach pieces date back to the1990s, an indication, perhaps, of the street-venerability of their creators. We ponder on the habits and sociability of these enigmatic artists, their empty beer cans and the remnants of their burnt out cardboard crates, strewn in semi-circles around vacant benches beside the canal, telling tales of urban gatherings. These traces summon visions of hard-core taggers and vagrants, convened like nomadic druids, around makeshift bonfires, exchanging their stories and secret knowledge away from prying eyes.

The inner city slips away and the view is replaced with an expanse of freight railway networks, depots, and churned up earth. Mossy railway bridges slink overhead, connecting the lines. Some industry occupies the opposite bank. The graffiti flourishes. The path narrows and we file between the canal and patches of shrubbery, stinging nettles, and high fences topped with razor wire.

On the outskirts of Wembley, where perhaps only the most hardened dogwalker would normally tread, we begin to notice a few shanty-like structures. Blankets and bits of corrugated metal are strapped to rusted girders that support elevated sections of disused, or barely used, factories and warehouses abutting the canal bank, the destitution unlike anything one would expect to see in $21^{\text {st }}$ century London. As we continue our solitary walking (how many people do we encounter in either direction?) more piles of empty Special Brew and White Lightning cans suggest that things are quite different here at night. I wonder whether these constructions are occupied, and, if so, by whom. Have they been moved on, which is not unlikely, or is there an unseen human presence, sleeping off a hangover and waiting for the next canal-side party? 


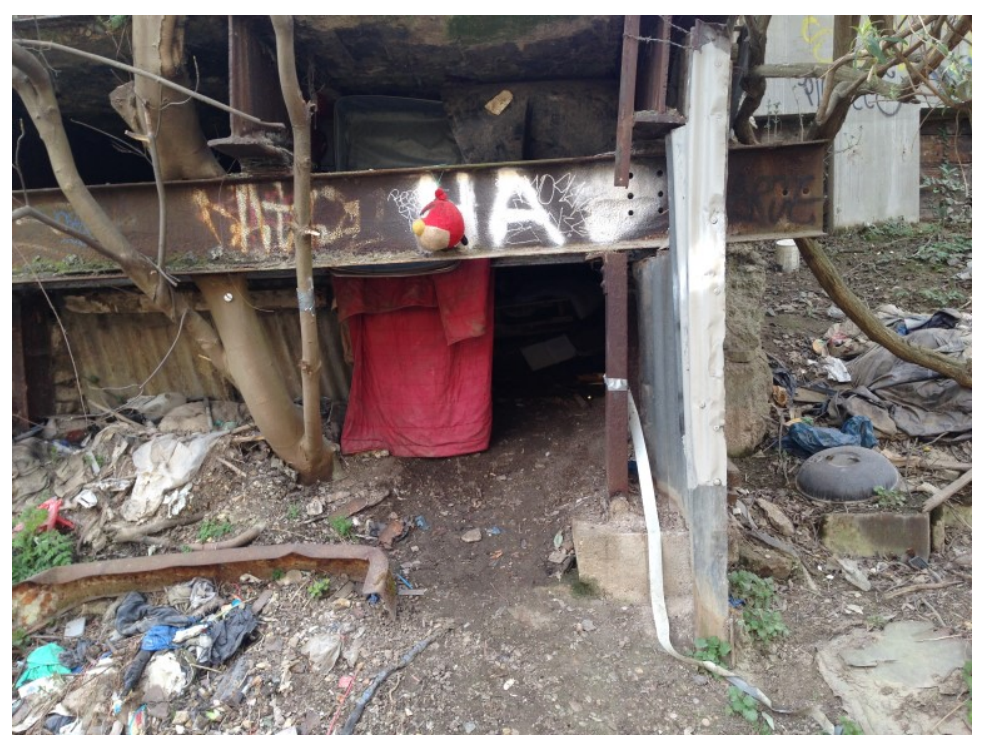

At the Twyford aqueduct, over the North Circular, we stage a

mythogeography-inspired intervention using a glass bottle we find on the tow path and a scrap of paper from my sketchbook to cast an improvised message in a bottle into the canal. In the prank-like spirit of Smith's critical practice, I jot something as equally absurdist and I hope, compelling, which in some way reaffirms, for ourselves, and any would-be finders of the message, what we are trying to do there.

Crossing the North Circular, we enter the heart of Metroland and for a while wander through clusters of communities that have formed quite haphazardly around the canal. Unsightly brown council houses are squashed into areas bounded by the canal, pockets of industrial recession, and railway intersections.

Between Stonebridge Park and Alperton, we discover an old cassette tape player cradled in a straggly, wind-blown shrub by the canal side. Inside, is a tape with the artist and title inscribed: By Mumbai, "The Sound of Sweetness." The batteries have long since died and we can only speculate what sounds the tape might play, who it had belonged to, and where it originated (I have since searched unsuccessfully for the tape online). We imagine a poignant story behind this fragment: of one man's plight in the big city. Perhaps a bit down on his luck, and missing home, this unseen character had retreated to the canal bank in order to relax in its relatively scenic terrain, a place where he could listen unmolested to the sounds of his homeland. For me, there was something anarchic, sublime even, in this possibility. 

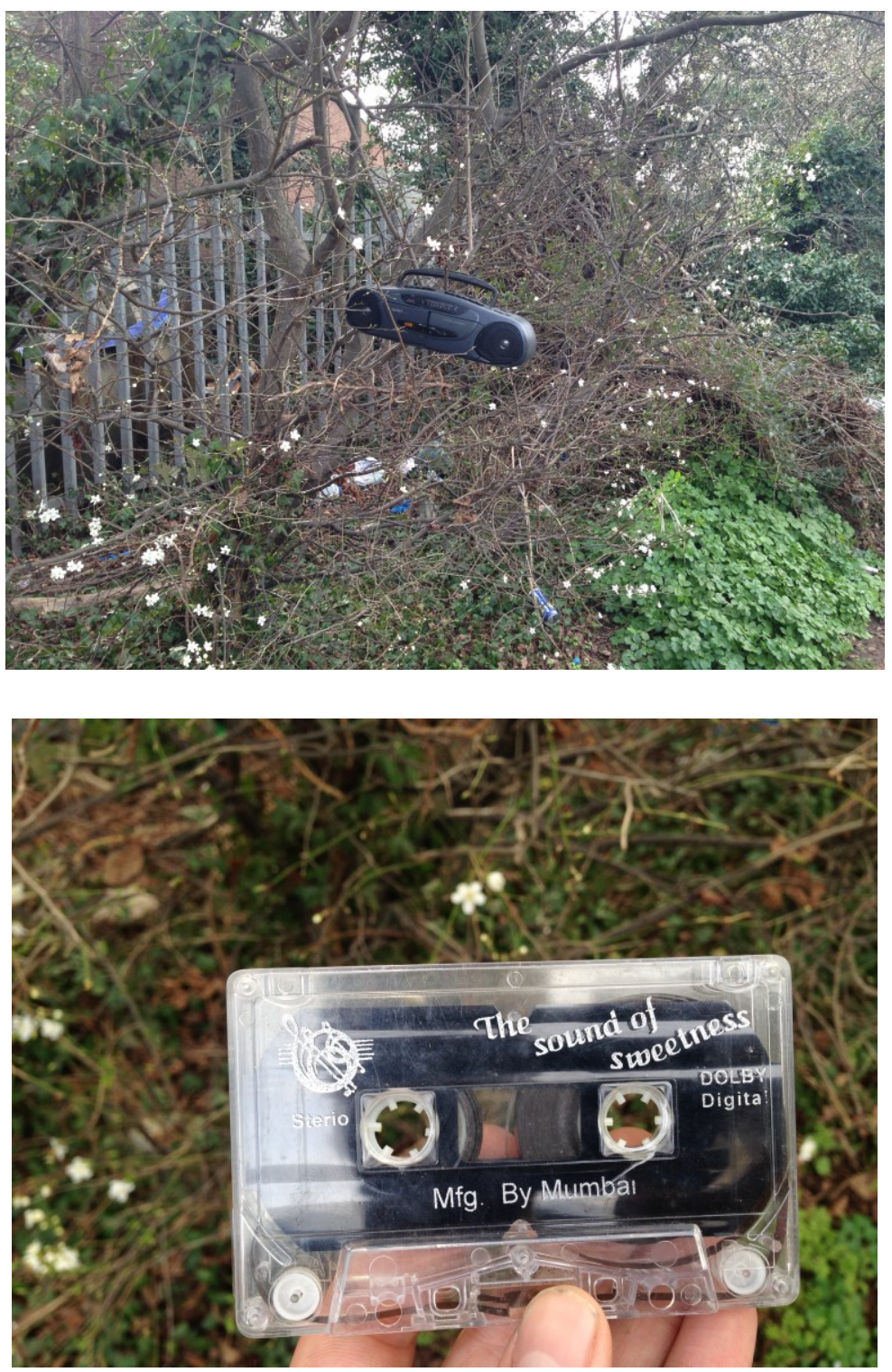

We finish our walk at Alperton, a very average London suburb that I have never visited before, and quite likely, will never visit again. A sign on the canal path informs us the next stops are Bath or Birmingham, both some 111 miles away, so it's an appropriate juncture, we agree, to conclude our drift. At the train station we bid our farewells and part company.

Rattling through London on the Piccadilly and Metropolitan lines and trying to make some sense of the walk and crystallise in my mind some of its high points, I perused the pictures I had taken on my iPhone. The tube passed through some of the suburbs we had seen on our walk. Elevated railway sections commanded a superior view of those disparate territories, but they commanded nothing of the now invisible people who lived there. The moment reminded me of the famous view described by Michel de Certeau from the top of the New York World Trade Centre, of the streets below, which could tell him nothing of the people who inhabited them. 


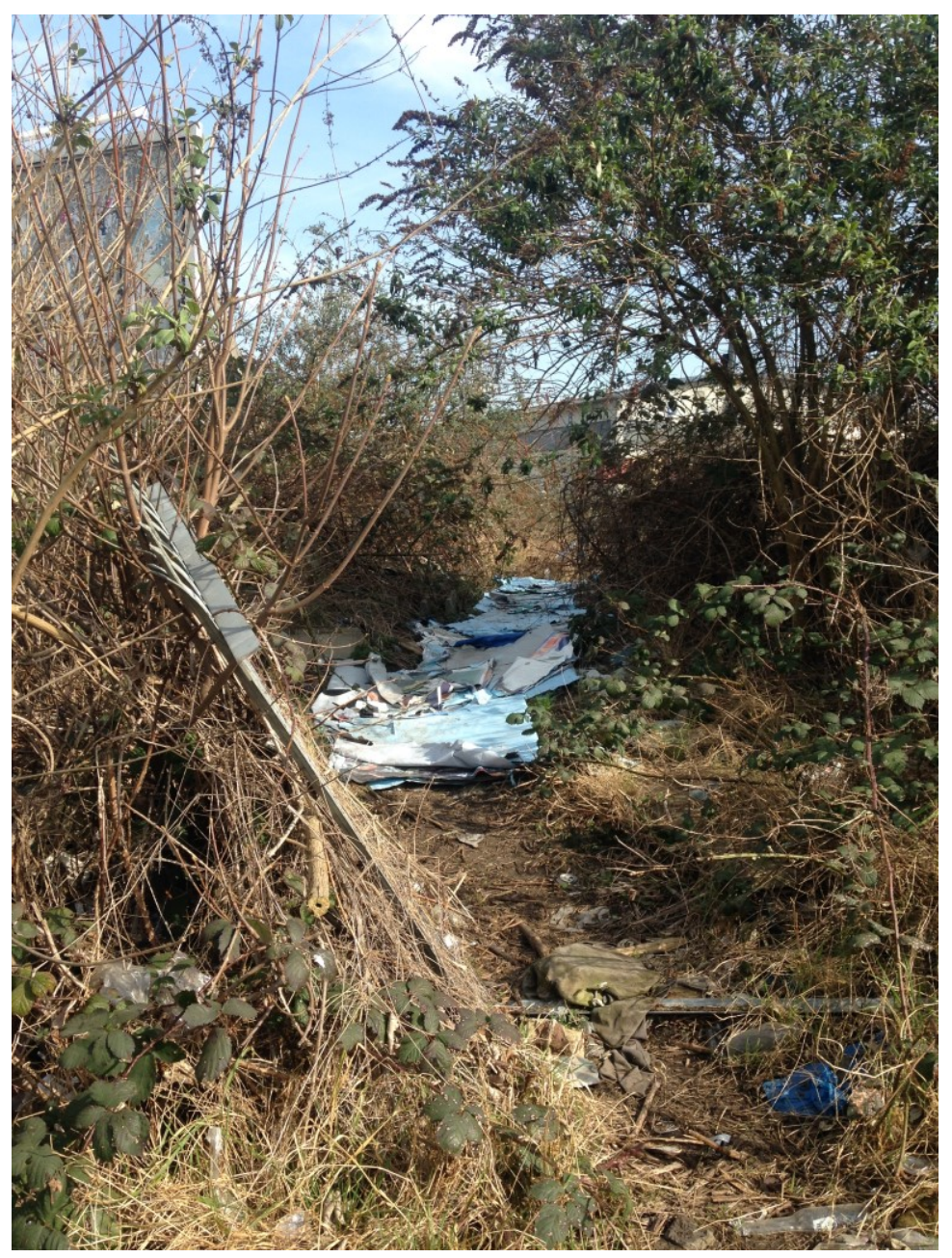

There was nothing radical, or overtly revolutionary about our walk. It didn't arise from a tactic that we had hoped would lead to tearing down the establishment from the inside out as the Situationists had planned, and failed to do, some sixty years earlier. That was not our intention. Our observations, experiences, and interactions with the physical environment, though, undeniably stimulated and informed our subjective perceptions of it in ways that cannot be conceived of through laboratory experiments, books, computer screens, or the totalizing views provided by conventional maps.

The sights and feelings I have described here might be considered poetic images. They were conceived through a culmination of lived experience, reverie, and self-conscious imaginative free play, and they opened up new worlds, of human possibilities and potentialities, beyond their initial encounter, as they impacted on our individual, and collective psyches. The phenomenologist Gaston Bachelard, perpetuated this idea that poetic images, found in the everyday, offer not only ephemeral moments of comfort and solidarity, but also extend the horizons of epistemology. They broaden the scope for understanding ourselves as people, and the question of where and 
how, we gather such information. The mental images we conceived of on our walk, the individual and collective memories we took away, the photographs we took, have become conversational pieces, the focus of critical discussion, and ways of making new connections between the built environment and the people who inhabit it.

\section{Coda}

That liberating, almost ethereal sense, I first experienced in those non-spaces some time ago, would never have been enough for me to re-visit them alone. My own rationality, and the pressing nature of the everyday, would not have permitted me to return on the grounds of such an ungrounded motive. Your invitation for a walk, chosen by me, was the catalyst for my return. Our shared experiences, and on-going dialogue, were essential in reifying those ghosts, and reconnecting with them. Self-consciously transforming the metaphysical nature of those territories, collectively, for me, could be the beginnings of a new urban awareness. I psychologically remapped a ghost territory that was situated somewhere between dream and reality on the peripheries of my consciousness. Psychologically remapping one site in a vast, but exhaustive list of many, in a metropolis as big as London, in this light, becomes a way of overlaying an on-going, and very personal, narrative, onto sites which might otherwise be reduced to coordinates on a map.

I wonder now, as I did then, about the role that Smith played in directing our thoughts and actions that day. Much of Smith's writing, prior to our walk, had brought to mind the activities of an anarchic movement known as Neoism, which from what I can tell, seemed to fizzle out at the end of the twentieth century. Its proponents too, based on the rather questionable existing accounts of their accomplishments, used collective pseudonyms, and promoted an ideology based on parody and subterfuge. They engaged in the propagation of such academically taboo subjects as ley lines, and dabbled in performance-based praxis, such as psychogeography. The group notably, and hilariously, through their writings, on a number of separate occasions, tricked journalists, who had failed to do their research, into publishing articles based on entirely fabricated ideas and events.

Naturally, (as I'm sure you can understand), I had my reservations about following Smith's writing so rigidly. There was this worrying sense that we were walking, quite literally, deeper and deeper, into the clutches of an old practical joke, designed to ensnare academics and social commentators. Then again, engaging, perhaps loosely, as we did, with something as autonomous and free-floating as Smith's methodology is precisely the open-ended approach urban epistemology requires. Adopting a droll sense of humour, in 
tandem with an acute critical awareness towards the built environment, and the everyday, recalls that dialectic I had set out in search of. I maintain now, we cannot leave our futures purely in the hands of academics, sociologists, and rather turgid twentieth century critical texts, which can bear little, or no relation, to present circumstances. Reality and lived situations are so much more affecting. So long as we come to terms with the fact that the immediate act of walking is not going to physically change the landscape, not remarkably anyway, the possibilities for future change, physical or metaphysical, are limitless.

Mythogeography, urban walking, and drifting, all seem superficially quite egocentric, instantly gratifying, and perhaps self-indulgent, but then I have to ask, how are we as artists, and human beings even, ever going to change the world, except by first experiencing it for ourselves? Changing the world is a gradual process. I also believe it can be both physical, and metaphysical, and I would argue that the latter, is actually more significant and meaningful. I would not describe our walk together as an instantly revelatory or life changing experience, and do not think the next one will necessarily be so either. My epiphany has been that walking should be a never-ending process, a critical tool at our constant disposal, for reconnecting disconnected territories, and reconciling ourselves with those territories, giving birth to new ideas about the nature of cities and everyday urban life. 